\title{
Fear Factor: The Role of Media in Covering and Shaping the Death Penalty
}

\author{
Susan Bandes*
}

\section{INTRODUCTION}

Now that there is a book of academic writing available about the Simpsons (The D'oh of Homer'), perhaps a reference to a scene from that show might have the proper academic cachet. When Sideshow Bob is caught redhanded attempting to kill his brother, Police Chief Wiggams wheels the gurney up to Bob and prepares to strap him in. Bob asks, "Isn't it customary to have a trial first?" and Wiggams replies, "Oh, a wise guy, eh?" As we read media accounts of the jurisdictional jockeying over who would get to impose a death sentence on accused D.C. area snipers John Mohammad and Lee Malvo before they were brought to trial, or about the Illinois clemency hearings in which the cries for execution drowned out discussion of serious flaws with the administration of the death penalty, we might ask whether Chief Wiggams' attitude toward procedural protections is confined to the cartoons.

Substantial work has been done on media's coverage of crime, in particular its insistent focus on violent crime. Very little work has been done specifically on media's relationship to the death penalty. Although much of what has been said about media and crime is highly relevant to this topic, the death penalty presents its own complex set of challenges for the media, and these are the focus of this piece.

Law and media exist in a complex feedback loop. Television, with some help from other media, has become our culture's principal storyteller, educator, and shaper of the popular imagination. ${ }^{2}$ It not only transmits legal norms, but also has a role in creating them. We are constantly constructing and interpreting our notions of law and justice based on what we know, or what we think we know. Relatively few people have direct experience with the criminal justice system, and so much of what we know, or think we know, comes from media coverage. We should focus on media's limitations, their potential, and their particular grammar and logic, because these have important implications for our ability to articulate, construct, and even deliver justice.

What is meant by "media?" The word is plural, and in one regard, it is important to treat it as such-focusing on the particular characteristics of each individual medium. Television, the omnipresent medium, has a particular

- Distinguished Research Professor of Law, DePaul University. I wish to thank Bill Bowers, Jim Liebman, Andrea Lyon and Michelle Oberman for their comments on an earlier draft.

1 The Simpsons AND Philosophy: The D'OH! Of HoMER (William Irwin et al. eds., 2001).

2 Susan Bandes \& Jack Beermann, Lawyering Up, 2 GreEN BAG 2D 5, 6 (1998). 
grammar, and the nature of the information we receive is to a great extent shaped by that grammar. I do not suggest that this grammar is inherent in the technology; there are complex explanations having to do with corporate imperatives, audience psychology, and the political and social landscape. But descriptively, we can say that television uses an episodic frame that "fragments information into isolated, dramatic particles and resists longer and more complex messages." ${ }^{3}$ It emphasizes immediacy and discrete occurrences. It prefers simple, dramatic messages that resonate with what we already know-heroes, villains and other familiar stock figures, right and wrong, easily identifiable problems with simple solutions. It is better at showing the status quo than the need for change, better at the concrete than the abstract or nuanced. Other media have different rules and limitations, and though the differences are important, it is also true that the media bathe us in a "seamless torrent," and this torrent supplies a message that in important respects feels quite uniform. More to the point, the folk knowledge that we construct from "the media" does not tend to distinguish among particular media, or even, in many cases, between news and entertainment. ${ }^{5}$ For that reason, I will generally refer to "the media" in this paper, reserving a more particularized look at various media for another day.

\section{DISCRETE OCCURRENCES}

The modern sound bite does not just shape how the news is covered. It alters the very character and definition of issues and events." "What is simple, fragmented, short-term or localized plays well on the tube; what is compound, integrated, long-term, or general, does not." "7 The focus on breaking news-on immediate and discrete occurrences-has had well documented effects on crime coverage. Violent crime is television-friendly because it consists of (or is portrayed as consisting of discrete, dramatic, visual incidents between individuals. $^{8}$ The amount of airtime devoted to violent crime far outstrips the amount of such crime. Murder and other especially violent crimes receive by far

\footnotetext{
3 Jeffrey Scheuer, The Sound Bite Society: Television AND the American Mind 9 (1999).

4 Todd Gitlin, Media Unlimited: How the TORRENT of IMAGES AND SOUNDS OVERWHELmS OUR LIVES 7 (2001).

5 See George Gerbner, Television: The New State Religion?, 34 ET CETERA 148 (1977) (noting "[t]he same viewers watch them all; the total system as a whole is absorbed into the mainstream of common consciousness").

6 See SCHEUER, supra note 3, at 81 .

7 Id. at 87.

8 Jeremy H. Lipschultz \& Michael L. Hilt, Crime and Local Television News: DRAMATIC, BREAKING, AND LIVE FROM THE SCENE 2 (2002).
} 
the most attention, though they are the least common. ${ }^{9}$ Crimes committed by strangers, and crimes committed by blacks against white victims, are also far more prevalent in the media than in actuality. ${ }^{10}$ Thus the media create and feed on fears and passions about crime that are not well linked to reality, and these fears and passions have often led to solutions poorly tailored to address the most pressing challenges of crime control and adjudication.

Death eligible crimes tend to be violent, high profile, and thus by definition newsworthy under the "if it bleeds, it leads" criteria that govern media coverage decisions. In certain respects, the protocols and limitations of media are especially problematic for death penalty coverage. The focus on occurrence and immediacy is problematic. The coverage of capital crime, as journalist David Protess documents, "is event centered, surfacing in bursts that center on official developments." "It begins with a flurry of coverage of the crime, which tends to be, in these cases, especially dramatic and upsetting. It focuses on the investigation, and this very focus becomes an important fact of the investigative effort. It focuses on the trial: as a chance to replay gory details of the crime, as a drama with heroes and villains, and as a horse race-acquittal or conviction, death sentence or not.

What else counts as an occurrence in a capital case? The appellate procedure rarely does, even when it results in reversal. ${ }^{12}$ In general, it is portrayed as a kind of perpetually stale news (procedural problems with the original trial), or alternatively, as an endless and needlessly cruel delay, due to technical difficulties, in reaching the occurrence that matters-the execution. ${ }^{13}$ The execution is no longer inherently newsworthy; the fact and process of execution have been normalized through repetition. Journalists focus on the minutiae of the execution, on firsts (first execution in Illinois, first woman executed, first use of lethal injection) or lasts (last words, last meal, last appeal, last walk to death chamber) or on occurrences with shock value (malfunctioning electric chair, monster behind

9 See Sara Sun Beale, What's Law Got to do With It? The Political, Social, Psychological and Other Non-Legal Factors Influencing the Development of (Federal) Criminal Law, 1 BUFF. CRIM. L. REV. 23, 39 (1993).

10 LIPSCHULTZ \& HILT, supra note 8, at 117.

11 David Protess, Last Chance for the Condemned: Do Media Matter in Gubernatorial Clemency Decisions?, 2 CHI. POL'Y REV. 93 (1997).

12 Professor James Liebman discusses what he terms the problem of "weak feedback from reversals." James S. Liebman, The Overproduction of Death?, 100 COLUM. L. REV. 2030, 2119-21 (2000). As he observes, despite the extremely high rate of reversal in capital cases, there is no effective feedback loop from the post-trial stage to the trial stage. He discusses several factors interfering with effective feedback, including that the reversal when it occurs is too attenuated in place and time from the original occurrence, that the eventual correction generally is nothing more than a "slap on the wrist," and that this slap on the wrist is sustained by different state actors than those who committed the original errors. Id. at 2121.

13 See, e.g., LIPSCHULTZ \& HiLT, supra note 8, at 103 (noting that coverage of last minute appeals in one case came to symbolize public frustration with a justice system that took sixteen years to execute a condemned man). 
bars) or on the dramatic emotions we expect-the survivors' hope for peace and closure, for example. (Survivors who do not support the death penalty have often been silenced; ${ }^{14}$ they do not fit the stock expectations of the genre.) The questions raised by capital punishment-its moral underpinnings, its efficacy, its appropriateness, the problems with its implementation-are rarely addressed in the coverage of these individual cases, and even more rarely addressed in a systemic context.

Procedural issues are not filmic. More problematic, they have acquired a particular TV reputation: they are fancy lawyer tricks, exploitative technical ways of helping the obviously guilty escape consequences for what we all know they have done. ${ }^{15}$ Under the best of circumstances, procedural issues seem stale, abstract, complex, non-visual. Procedural arguments tend not to videotape well, and are poorly reduced to sound bites. They do not map onto stock dramatic terrain-guilt and innocence, good and evil. One of the greatest hurdles to covering capital cases is that the conflict is often not over guilt or innocence, but over sentence. The notion that one may have committed a crime worthy of punishment, but not of a death sentence, is too nuanced to fit any recognizable dramatic category. There is some evidence that high profile stories of false conviction have begun to erode public support for the death penalty. ${ }^{16}$ But what of those who committed a crime, but may not be "worthy of execution"? There are few telegenic models for conveying this sort of injustice. We remember Karla Faye Tucker, who was attractive, reformed, a born again Christian, and had Bianca Jagger and Pope John Paul II on her side, and realize how rare such crowdpleasing personae are on death row.

The controversial clemency hearings recently held in Illinois illustrate the difficulty of conveying the human dimension of procedural failure. The hearings were requested by the prosecution after Governor Ryan announced his intention to consider clemency for all death row inmates. These hearings dealt with cases in which "technicality" hardly described what was at stake for the defense. Thirteen men in Illinois had been exonerated after years on death row-more than the twelve who had been executed. Of those remaining, ten had credible allegations that they had confessed due to torture. Others had been convicted by all white juries, or based on uncorroborated testimony of jailhouse snitches, or had been represented by disbarred and otherwise ineffective counsel, or were mentally retarded-virtually the whole panoply of errors going to the heart of the death penalty's fairness. As the Chicago Tribune reports, "Prosecutors and victims'

14 See Robert Renny Cushing \& Susannah Sheffer, Dignity Denied: The Experience of Murder Victims' Family Members Who Oppose the Death Penalty, Murder Victims' Families for Reconciliation (Aug. 2002), available at http://www.mvfr.org.

15 David A. Harris, The Appearance of Justice: Court TV, Conventional Television, and Public Understanding of the Criminal Justice System, 35 ARIZ. L. REV. 785, 815 (1993).

16 Samuel R. Gross \& Phoebe Ellsworth, Second Thoughts: Americans' Views on the Death Penalty at the Turn of the Century, in BEYOND RePair? AMERICA's DEATH PENALTY (Steven P. Garvey ed., 2003). 
families immediately put in place a strategy from which they would not deviatepressuring Ryan with accounts of how murder victims and their families had suffered, while their killers were not deserving of anyone's mercy." 17 The strategy was successful with the media, which not only portrayed the defense arguments as technical, even beside the point, but painted the forum as itself a cruel and gratuitous punishment for the survivors forced to relive the crime once again. Commentator Dennis Byrne exemplified the tone of the coverage when he wrote about Governor Ryan; "[r]arely has a public official engaged in such a stunning act of cruelty." were presented as the true function of the legal system. The "depth of the families' pain and anger"19 drowned out all other voices, including those of the exonerated men and their families, who tried to speak of the pain and loss they had experienced. $^{20}$

Ultimately, Ryan's decision to pardon six men and to commute the sentences of all other death row inmates to life imprisonment without parole became a media-worthy event in its own right- garnering international attention. It is too early to evaluate the full scope of media coverage of this event and its aftermath, and the extent to which it will focus on the systemic procedural problems Ryan described in painstaking detail as explanations for his decisions. ${ }^{21}$ Predictably, much of the coverage has focused on raw emotion, and it is at least a mark of progress that it examines the emotions of the inmates and their families, as well as those of the victims' families. ${ }^{22}$ Much of the discussion of the more abstract issues of fairness and justice has focused on whether blanket as opposed to case-by-case commutation was appropriate. ${ }^{23}$ As to the issues of systemic failure that placed the former governor in the position to make that wrenching choice, it remains to be seen whether the media will address them in a sustained manner once this "incident" too passes from the limelight.

17 Steve Mills \& Maurice Possley, Decision Day for 156 Inmates, CHI. TRIB., Jan. 12, 2003, at $\mathrm{Cl}, \mathrm{C} 15$.

18 Dennis Byme, To Kill A 'Legacy', CHI. TrIB., Oct. 21, 2002, at CN17.

19 Mills \& Possley, supra note 17, at $\mathrm{C} 15$.

20 See, e.g., Jodi Wilgoren, Clemency Hearings Are Reviving Anguish of Illinois Crime Victims, N.Y. TIMES, Oct. 16, 2002, at A17 ("[W]hile the lawyers spoke in abstract terms about long-ago interrogations, failed motions and suspicious evidence, the survivors provided painful, personal portraits of crime.").

21 See Mills \& Possley, supra note 17.

22 See, e.g., Rudolph Bush \& Jeff Coen, Alive, Hopeful And Angry, 3 Get lst Taste of Freedom, CHI. TriB., Jan. 11, 2003, at 1; John Keilman, Murder Victims' Families Feel Twice Betrayed by Ryan, CHI. TRIB., Jan. 12, 2003, at C17.

23 See, e.g., Lucio Guerrero, Prosecutors, Survivors Rip Ryan, ChI. SUN-TimES, Jan. 13, 2003, at 7; Christi Parsons \& Karen Mellen, House Bill Seeks Limit on Blanket Clemency; GOP Challenges Governor's Sway, CHI. TRIB., Jan. 17, 2003, Metro Section, at 1; Eric Zorn, Ryan's Answers on Clemency are Deficient, CHI. TRIB., Jan. 16, 2003, Metro Section, at 1. But see Editorial, Obstruction of Justice, CHI. TRIB., Jan. 15, 2003, at N1. 


\section{RELIANCE ON OFFICIAL SOURCES}

Occurrence-driven reporting raises another problem for substantive, evenhanded death penalty coverage. The nature of an occurrence is largely keyed to governmentally defined and created milestones-arrest, investigation, trial, execution, clemency hearing. News coverage follows the structure and organization of police work, beginning, for example, at the scene of the crime, and focusing on arrest and charging. The primary sources for information are government sources: the police blotter, the police wire, the arrest report, the mug shot, the death order. The voices of authorities dominate the content of the coverage. Serious appellate issues are dismissed with official statements like, "the case has already dragged on too long."24 Executions are described in routine, distancing language, like, "keeping an appointment" with death. ${ }^{25}$ The defendant's voice is often not heard at all.

When a defendant is in prison, a host of additional hurdles arise. Even the most motivated media run into the increasing secretiveness of the prison system, a proliferation of rules punishing both prisoners and journalists for coverage. ${ }^{26}$ These onerous regulations exacerbate, but also track to a large extent, the media's own internal reluctance to cover prisons. Media do not tend to allocate funds for a "prison beat." Without video coverage, the story will not be filmic. Complex issues about prison conditions do not lend themselves to sound bites. The decision to focus on the prisoner's plight or seek out his perspective may be derided as "coddling criminals" or as a denigration of the lives and suffering of the victims.

Media savvy reformers may find a way to create an occurrence-a demonstration, for example - or better yet, a resonant theme, such as "innocent men on death row."27 But without the usual trappings-prepackaged conflict and immediate incidents-journalists tend to be uncomfortable seeking out stories of social problems requiring change. Such a role conflicts with their perception of themselves as impartial chroniclers. ${ }^{28}$ The upshot is a severe imbalance in the

24 Protess, supra note 11 , at 93.

25 LIPSCHULTZ \& HiLT, supra note 8, at 114.

26 See Peter Y. Sussman, Media on Prisons: Censorship and Stereotypes, in INVISIBLE Punishment: The Collateral Consequences of Mass ImPrisonment 263 (Marc Mauer \& Meda Chesney-Lind eds., 2002).

27 See, e.g., Alan Berlow, The Wrong Man, Atlantic MonThly, Nov. 1999, at 66, 86. Note in this regard the highly effective work of Larry Marshall, Rob Warden and David Protess at Northwestern Law School's Center on Wrongful Convictions, and of Barry Scheck and Peter Neufield at Cardozo Law School's Innocence Project. For a discussion of the work of the Center on Wrongful Convictions, see Lawrence C. Marshall, The Innocence Revolution and the Death Penalty, 1 Ohio ST. J. CRIM. L. 573 (2004).

28 Jane Amari, Is Crime Coverage Out of Balance? Research Shows a Need for More Reporting of Context, Perspective, Consequences, Risk Factors, NEwS WATCH (Gannett News Network) Mar. 12, 1999, available at http://www.gannett.com/go/newswatch/99/march/nw0312-1. htm. 
guise of neutrality. The reliance on occurrence becomes a reliance on the voice and priorities of government institutions, making journalists, as David Protess put it, "unwitting governmental partners." 29

\section{STARS AND VILLAINS}

Dramaturgy seems to require a focus on individual actors with clear, recognizable motives. Violent crime plays so well because it involves individuals doing obvious wrong to undeserving victims. Individuals are the nexus of responsibility for wrongdoing; and they can be styled as "blameworthy" in a way that is easy to understand. This notion of wrong and blame poses difficulties for the capital defendant who committed a crime, but perhaps not a crime worthy of death. It is also inhospitable to the concept of governmental wrong, or of systemic wrong, of the sort that is "often the result of cumulative actions and inactions by numerous officials," general, the episodic nature of media is poorly suited to exploring root causes, context, complex causal chains, or multi-faceted explanations, and thus the media rarely address systemic problems like the exclusion of black jurors, the reliance on jailhouse informants, the coercion of confessions, the ineffectiveness of counsel, or even more abstractly, issues of skewed resources, wholesale system breakdown, disproportionate sentencing, or deeply imbedded racial inequality. Examples of thoughtful, complex explorations exist in virtually every medium; ${ }^{32}$ but they are all too rare.

\section{MEDIA-FRIENDLY EMOTION}

Much of what I have said so far has dealt with media portrayals of crime, but there is a feedback loop at work. The death penalty is especially susceptible to the influence of media, at a number of crucial pressure points. The feedback loop is especially visible at the legislative juncture, when crime control policies are made; at the prosecutorial juncture, when discretion about capital charging is at work; and at the adjudicative juncture, when both judge and jury must make difficult decisions about sentencing.

29 Protess, supra note 11 , at 93.

30 Wilson v. Seiter, 501 U.S. 294, 310 (1991).

31 Owen v. City of Independence, 445 U.S. 622, 653 (1980); see also Susan Bandes, The Negative Constitution: A Critique, 88 MiCH. L. Rev. 2271, 2320-23 (1990); Susan Bandes, Patterns of Injustice: Police Brutality in the Courts, 47 BUFF. L. REV. 1275, 1325-35 (1999).

32 See, e.g., Ken Armstrong \& Steve Mills, Death Row Justice Derailed, CHI. TRIB., Nov. 14, 1999, at C1 (first of a five-part series). For an example of a thoughtful examination of a crime in a different medium, see Michael Moore's short treatment, in the film Bowling for Columbine, of the conditions that led to the shooting of one elementary school pupil by another in Flint, Michigan. 
Arguably, it is in the nature of the Eighth Amendment itself, with its reliance on community norms, to evoke and even incorporate certain emotional judgments, such as our collective sense of outrage, mercy, sorrow, disgust, or the desire for vengeance. But of course the Eighth Amendment asks for something more difficult than easy empathy with victims; it asks for a collective assessment of the acceptability of the death penalty, and it asks certain individuals to make the difficult emotional connection, at least at the penalty stage, with the defendant himself. $^{33}$. Unfortunately, only certain types of emotions, and certain emotional scripts, tend to be media-friendly. In general, these tend to be the simple emotional reactions evoked by familiarity, or even by stereotyping, rather than the more challenging emotional connections viewers could be pushed to make.

The media focus on violent crime is so evocative because it depicts a frightening rupture of the social order, one that must be put to rights before we can regain equilibrium. The coverage is steeped in expressions of intense anger toward violent criminals. How is the equilibrium to be regained?

The pervasive sowing of fear and outrage at the breach of security and social order tend to generate demand for retribution, for harsh sentences, and for an appropriately expressive public condemnation of the wound inflicted on the polity. ${ }^{34}$ On the policy-making level, this means that prisons continue to be built despite convincing evidence that expanding prison and death row populations is a wholly ineffective response to the problem of crime. ${ }^{35}$. It also means that the number of aggravating factors triggering death eligibility can only increase. Scott Turow eloquently described the dynamic:

[I]f death is available as a punishment, the furious heat of grief and rage that these crimes inspire will inevitably short-circuit any capital system. Now and then, we will execute someone who is innocent, while the fundamental equality of each survivor's loss creates an inevitable emotional momentum to expand the categories for death penalty eligibility. ${ }^{36}$

\section{CHARGING}

The charging process is a negotiation, a highly visible interplay among legal actors, media, and the public. Intense media focus on high profile violent crime

33 See Susan Bandes, Empathy, Narrative, and Victim Impact Statements, 63 U. CHI. L. REV. 361, 393-410 (1996).

34 See Dan M. Kahan, The Progressive Appropriation of Disgust, in THE PASsIONS OF LAW 63 (Susan A. Bandes ed., 1999).

${ }^{35}$ See Beale, supra note 9, at 29 (citing Marc Mauer, Take a Life out of Crime, RECORDER, Sept. 11, 1996, at 4).

36 Scott Turow, To Kill or Not to Kill: Coming to Terms with Capital Punishment, THE NEW YORKER, Jan. 6, 2003, at 40, 47. 
creates "heater cases." ${ }^{37}$ This term sums up one aspect of the tight symbiosis between crime and media. The high profile of the case, the constantly ratcheted need to find a killer who seems increasingly monstrous as he remains at large, produces a well recognized pressure on law enforcement to solve the crime. The media up the ante for both police and prosecution by stirring up passion about the crime. ${ }^{38}$ Recently, this dynamic was visible in the case of Scott Peterson, charged with capital murder after intense media coverage of the disappearance of his lovely, young, pregnant wife Lacie. ${ }^{39}$ District Attorney Jim Brazelton said: "This case cries out for the ultimate punishment. ... I owe it to Lacie and [her unborn baby] Connor., ${ }^{, 40}$ A neighboring district attorney observed in relation to the capital charge: "As long as district attorneys are elected county officials, they have to do what the residents want, within the dictates of the law." 41

At times the media may facilitate empathetic connections, may humanize and create compassion for an accused or condemned person, as it did with Karla Faye Tucker and Andrea Yates. Tucker was executed despite (some might say because of) media attention; in Yates' case it is possible that public sympathy contributed to the Harris County prosecutor's unusually half-hearted pursuit of the death penalty. But the concern is that the media's selective empathy will reflect and exacerbate the already existing race and class-based inequities in death penalty charging and implementation. ${ }^{42}$

In the absence of these rare bursts of compassion, the more usual case is one in which the accused tends to be portrayed as a decontextualized monster. In such cases, righting the equilibrium and responding to pervasive fear tend to translate into the demand that the defendant be put to death. The stock story is that of the

37 Myron W. Orfield, Jr., Deterrence, Perjury and the Heater Factor: An Exclusionary Rule in the Chicago Criminal Courts, 63 U. CoLo. L. REV. 75 (1992).

38 See, e.g., Turow, supra note 36 , at 42 (noting that "a frightened public demanding results in the aftermath of a ghastly crime ... places predictable pressures on prosecutors and police" and describing this dynamic as it worked in the Illinois prosecution of Rolando Cruz and Alex Hernandez).

39 For a humorous take on the media-saturation phenomenon, see CNN, Fox Promise 'Orderly Transition' to 24-Hour Modesto Murder Coverage, The Borowitz Report, Apr. 20, 2003, at http://www.borowitzreport.com/archive_rpt.asp?rec=579.

40 Harriet Chiang, How Prosecutors Choose Death Penalty, SAN Fran. Chron., Apr. 24, 2003, at A1.

41 Id.

42 See, e.g., William J. Bowers, Benjamin D. Steiner \& Marla Sandys, Death Sentencing in Black and White: An Empirical Analysis of the Role of Jurors' Race and Jury Racial Composition, 3 U. PA. J. CONST. L. 171, 260 (2001) (reporting findings that in juries studied, whites were more likely than blacks to see black defendants as dangerous to society in the future and as likely to get back on the streets if not sentenced to death); U.S. GenERAL ACCOUNTING OfFICE, REPORT To SENATE AND house Committees on the Judiciary, Death Penalty Sentencing: Research Indicates PATTERN OF RACIAL DisPaRITIES (Feb. 26, 1990), available at http://www.gao.gov/ index.html. 
survivor who needs the defendant to die in order to achieve closure. ${ }^{43}$ This need is presented as an entitlement the state owes the defendant, or risk denigrating the worth and dignity of the victim. ${ }^{44}$ The idea that not every victim or survivor desires, needs, or deserves an execution introduces unwelcome layers of complexity. The portrayal of the wrongdoer as anything less than purely evil, and entitled to any consideration at all, comes to be seen as relativistic, a threat to the social order and to our ability to protect ourselves from harm. ${ }^{45}$

As we have witnessed all too often-recently in the Rolando Cruz case and the Central Park jogger case-heater cases are ripe for police and prosecutorial overreaching and misconduct, and for false convictions. The anger, the sense of breach, demand that the equilibrium be righted, and at times it seems less important that it be righted with the correct person than that some sort of closure occur. ${ }^{46}$

In Part II of the landmark study, A Broken System, ${ }^{47}$ James Liebman and his co-authors seek to identify factors related to serious reversible error in capital trials and verdicts. The Columbia study authors find, among other variables, that (1) states with higher African-American populations relative to the total population have significantly higher rates of serious error, and (2) the more heavily the risk of homicide is concentrated on a state's white community compared to its black community, the higher the rate of reversible capital error. They provide a provisional explanation, that:

If people with political influence feel not only that they live in a high-crime environment and are often the victims of violent crime, but, in addition, that they might be targeted for crime by members of a different group, pressure to increase the use of the death penalty (even in marginal or weak cases where the need to

43 See Susan Bandes, When Victims Seek Closure: Forgiveness, Vengeance and the Role of Government, 27 FORDHAM URB. L.J. 1599 (2000).

44 See Steve Mills \& Ray Long, Cruz, 2 Others Pardoned, CHI. TRIB., Dec. 20, 2002, at N1, N20 (reporting that Governor George Ryan "said he was perplexed that the families of some murder victims feel entitled to an inmate's execution").

45 See Joseph E. Kennedy, Monstrous Offenders and the Search for Solidarity Through Modern Punishment, 51 HASTINGS L.J. 829, 904 (2000).

46 See Steve Mills, Life-or-death Debate Rages at Hearings, CHI. TRIB., Oct. 16, 2002, at N1, N14 (reporting that "in some hearings, victims' families said an execution was the only way they would achieve emotional peace"); see also Berlow, supra note 27, at 77 ("In gruesome, high profile cases ... a defendant may go to trial with a theoretical presumption of innocence but he or she will have a difficult time proving that innocence.... [T] he more violent and vicious the crime, the more likely a jury is to convict.").

47 James Liebman et al., A Broken System, Part II: Why There Is So Much Error in Capital Cases, and What Can be Done About It? (Feb. 11, 2002), available at http://www2.law.columbia.edu /brokensystem $2 /$ index 2 .html. 
cut corners to obtain conviction or sentence is great) might be especially high. ${ }^{48}$

Although the authors correlate the risk of error with the presence of verifiable factors (numbers of African-Americans in proportion to whole population; actual risk of homicide), it is arguable that the perception of a threat of black-on-white crime, even if it were inaccurate, would produce exactly the same pressures they describe. Indeed, their working hypothesis refers to what people of political influence "feel." And the perceptions that would tie most directly to the risks they identify - that our communities are riddled with violent crime, that it is perpetrated on strangers, and that it is most often perpetrated by black men on white victimsare precisely those that the media have been instrumental in conveying.

\section{SENTENCING}

The Columbia study strongly suggests that counter-productive pressure can be brought to bear at the charging stage, but it also suggests that the fear factor has a pernicious effect at later stages of capital litigation. There is other evidence that this is true, as to both juries and judges.

Convincing empirical evidence exists that fear is one of the most prominent factors influencing jury decisions to impose capital sentences. Specifically, juries are fearful that even if they impose a sentence of life without parole, the defendant will be released and perhaps cause more harm. The Capital Jury Project has demonstrated that jurors have significant misconceptions about the meaning of life without parole. When judges fail to address these misconceptions, the resulting confusion acts to the defendants' detriment. Juries will impose death sentences, often reluctantly, believing it is the only way to keep the defendant permanently off the street. ${ }^{49}$ The Capital Jury Project found that, in the absence of a judicial explanation to the contrary, jurors would fall back on the accepted folk wisdom that murderers are out on the street far too soon, and that early release is the norm. It was able to document that the media play a key role in reinforcing and reproducing erroneous folk knowledge about length of sentence. ${ }^{50}$ More generally, of course, jurors are not exempt from the pervasive media images of the world as a

48 Id. at $166-67$.

49 See William J. Bowers \& Benjamin D. Steiner, Death by Default: An Empirical Demonstration of False and Forced Choices in Capital Sentencing, 77 TEX. L. REV. 605, 643-71 (1999); The Constirution Project, Mandatory Justice: Eighteen Reforms to the Death PENALTY 17-18 (2001), available at http://www.constitutionproject.org/dpi/MandatoryJustice.pdf.

so See Benjamin D. Steiner, William J. Bowers \& Austin Sarat, Folk Knowledge as Legal Action: Death Penalty Judgments and the Tenet of Early Release in a Culture of Mistrust and Punitiveness, 33 LAW \& SoC'Y REV. 461 (1999); see also Stephen P. Garvey, Sheri Lynn Johnson \& Paul Marcus, Correcting Deadly Confusion: Responding to Jury Inquiries in Capital Cases, 85 CORNELl L. REV. 627 (2000). 
dangerous and violent place in which the criminal justice system has done too much for criminals and not enough to keep law-abiding citizens safe. ${ }^{51}$

Nor are judges exempt, much as we might like to believe otherwise. We need only observe the conduct of judicial elections to gauge the importance of media's role in judicial selection and even judicial behavior-and the salience of capital punishment in that media role. The vast majority of states with capital punishment statutes elect their judges, and in these states, "it is highly implausible that a candidate who refused to take a strong position in favor of the death penalty could be elected." 52 Studies show that judges facing re-election are more likely to impose a death sentence than juries hearing the same evidence, ${ }^{53}$ and that their death verdicts are "more likely to be seriously flawed than verdicts presided over by judges facing less political pressure." 54

Why is the death penalty such a salient issue for judges? The media play an important role both in creating the culture in which being tough on crime is all, and in reducing judicial races and even judicial decisions to simplistic sound bites. Judges who seek to flout conventional wisdom and uphold procedural safeguards are pilloried. ${ }^{55}$ The media, as we've seen, are not often inclined to convey procedural complexities. Even the most serious errors tend to be reduced to sound bites that translate to "he let him off on a technicality because he is soft on crime." 56 In the particular context of judicial races, judges are placed in the position of needing to create those very sound bites, and there is no substitute for touting one's own demonstrated commitment to the death penalty, or attacking that of one's opponent, as a quick and easy way to garner media attention and prove that one is not soft on crime.

\section{CONCLUSION}

Could media convey more progressive or at least more complex messages? Could they lead and challenge rather than pander, speak to our heads as well as our hearts, our better nature as well as our base instincts and fears? No doubt they could, if the right constellation of factors existed. Certainly the media are just one

51 See Steiner, Bowers \& Sarat, supra note 50, at 465 . The researchers found that jurors also firmly believe the death sentences they impose will be reversed on appeal. See id. at 485 .

52 Berlow, supra note 27, at 80 .

53 Stephen B. Bright \& Patrick J. Keenan, Judges and the Politics of Death: Deciding Between the Bill of Rights and the Next Election in Capital Cases, 75 B.U. L. REv. 759, 793 (1995).

54 Liebman, supra note 12, at 2111.

5s Bright \& Keenan, supra note 53, at 784-92. Obviously political pressure will have at least as great an effect on other elected officials, including governors who must decide whether to grant clemency to death row petitioners. See Berlow, supra note 27, at 78 .

56 See Harris, supra note 15, at 815 (discussing television's reduction of the criminal justice system to "a series of technicalities ... petty rules irrelevant to guilt ... [that] hamstring the police and benefit undeserving criminals"). 
factor in the complex interplay of ideological, political and social forces that give capital punishment such alarming resonance and staying power in this country. Nevertheless, they are a significant factor, and surely more than just a mirror or a messenger. It is well established that the media present distorted images of crime and justice. These images have serious consequences, including, as I have sought to demonstrate, a pernicious influence on the American system of capital punishment, both in the aggregate and in its application to individuals. The consequences are grave for those on trial for their lives, to be sure, but they also affect police, prosecutors, defense attorneys, jurors, judges, victims' families, the public - the whole universe of those who are supposed to make the criminal justice system work, and those whom it is meant to serve. The susceptibility of our system of capital punishment to media-perpetuated fears and passions raises unavoidable questions about who bears the responsibility for media reform and, ultimately, about the viability of a system that decides life and death in a mediasaturated context. 
